\title{
Study on Influencing Zone of Thermal Bridge of Corner Column in Self-insulation System
}

\author{
Shaobin Dai, Yichao Zhang ${ }^{*}$, Jun Huang and Qingrong Ni \\ School of Civil Engineering and Architecture, Wuhan University of Technology, Wuhan 430070, China
}

\begin{abstract}
The two-dimensional steady heat transfer of corner column is analyzed using ANSYS, moreover, influencing zone of thermal bridge and heat loss in influencing zone is analyzed quantitatively. Research shows that when the thickness of insulation layer is more than $20 \mathrm{~mm}$, influencing zone of thermal bridge is about $160 \mathrm{~mm}$, and additional heat flow in influencing zone accounts for more than $20 \%$ of additional heat flow in thermal bridge.
\end{abstract}

Keywords: Corner column, heat flow, influencing zone of thermal bridge.

\section{INTRODUCTION}

Exterior wall is an important part of building structure, and the heat loss from exterior wall is about $30 \%-45 \%$ of building energy consumption [1-2]. In order to promote the heat insulation performance of wall, the heat conductivity coefficient of wall material is lower and lower, leading to the effect of thermal bridge more notable. The existence of thermal bridge leads to the average heat conductivity coefficient of exterior wall increasing. According to the research, the energy consumption from thermal bridge can reach $20 \%$ [3]. Therefore, the heat transfer analysis of thermal bridge has significant meaning.

At present, one-dimensional weighting method is still used to calculate the thermal bridge in energy-efficiency design in China. However, the nearby zone of thermal bridge is affected by the heat transfer, which is called influencing zone of thermal bridge [4]. Using steady or unsteady heat transfer method, there were already some researches about thermal bridge [5-9], but few about influencing zone of thermal bridge [10]. Moreover, the research on influencing zone of thermal bridge was only focused on the condition of none heat insulation in thermal bridge. Furthermore, the quantitative analysis of it was still blank. According to this phenomenon, influencing zone of thermal bridge and heat loss in influencing zone was comprehensively analyzed in this paper.

\section{MATHEMATICAL MODEL}

The two-dimensional steady heat transfer model for thermal bridge is used:

$$
\frac{\partial^{2} t}{\partial x^{2}}+\frac{\partial^{2} t}{\partial y^{2}}=0
$$

The third boundary condition is used:

Inner surface of wall:

$-\left.\lambda \frac{\partial t}{\partial y}\right|_{y=\delta}=\alpha_{1}\left(t_{f 1}-t_{w 1}\right)$

Outer surface of wall:

$-\left.\lambda \frac{\partial t}{\partial y}\right|_{y=0}=\alpha_{2}\left(t_{w 2}-t_{f 2}\right)$

In the equation, $\alpha_{1}$ is the convective heat transfer coefficient of inner surface, which is $8.7 \mathrm{~W} /(\mathrm{m} 2 \cdot \mathrm{K}), \alpha_{2}$ is the convective heat transfer coefficient of outer surface, which is $23.0 \mathrm{~W} /(\mathrm{m} 2 \cdot \mathrm{K})$. Heating condition in winter in Wuhan is analyzed as an example, and $t_{f 1}$ is the indoor air temperature, which is $18^{\circ} \mathrm{C}, t_{f 2}$ is outdoor air temperature, which is $2{ }^{\circ} \mathrm{C}$.

\section{CALCULATION MODEL}

The typical thermal bridge of corner column is selected as the research object. Calculation model is shown in Fig. (1). The column material is reinforced concrete, the thermal insulation material is inorganic thermal insulation mortar, and the exterior wall is ultra-light aerated concrete block. By changing the insulation layer thickness of thermal bridge, influencing zone of thermal bridge and heat loss in this zone is analyzed quantitatively.

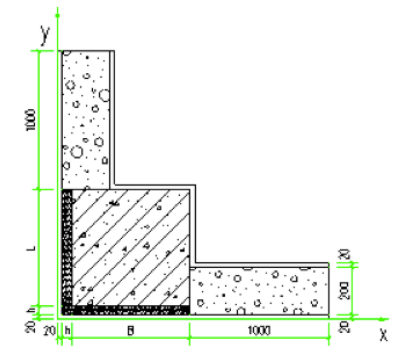

Fig. (1). Calculation model.

2015 Bentham Open 


\section{ANALYSIS OF RESULTS}

According to Fig. (1), temperature and heat flow of outer surface can be obtained, which can determine the influencing zone of thermal bridge and heat loss in this zone using ANSYS.

\subsection{Influencing Zone of Thermal Bridge}

The ratio of temperature difference at point $\mathrm{P}$ can be defined as:

$\xi=\frac{t_{f 1}-t_{p}}{t_{f 1}-t_{f 2}}$

In the equation, ${ }^{t}{ }_{p}$ is the temperature of any point $\left({ }^{\circ} \mathrm{C}\right)$.

The ratio of temperature difference in general place of outer surface:

$\xi^{\prime}=\frac{t_{f 1}-t_{2}}{t_{f 1}-t_{f 2}}$

In the equation, $t_{2}$ is the temperature in general place of outer surface $\left({ }^{\circ} \mathrm{C}\right)$.

Influencing zone of thermal bridge is the point which can meet the requirement:

$\frac{1-\xi}{1-\xi}<0.95$

The temperature distribution of corner column is shown in Fig. (2) (take $\mathrm{h}=50 \mathrm{~mm}$ for example). The temperature of different models is shown in Fig. (3).

As is shown on Fig. (3), when $\mathrm{h}=0$ (none heat insulation for thermal bridge), the influencing zone of thermal bridge is $0.08 \mathrm{~m}$, and with the thickness of insulation layer increasing, the influencing zone of thermal bridge is increasing obviously, and when $\mathrm{h} \geq 20 \mathrm{~mm}$, the growing trend is slow.
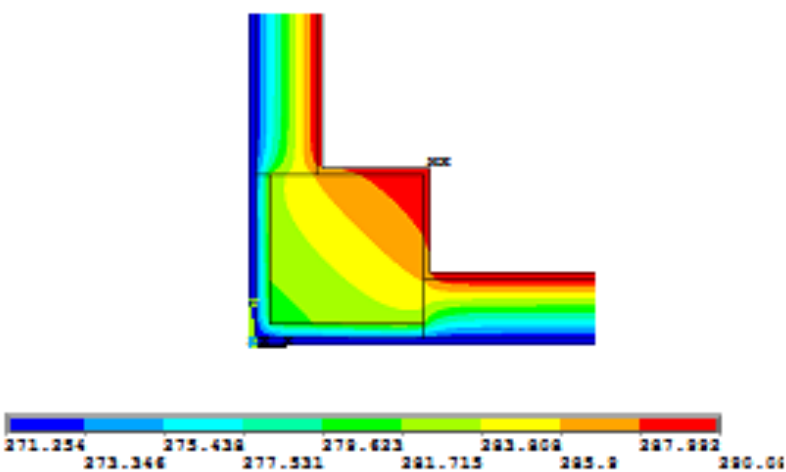

Fig. (2). Temperature distribution $(\mathrm{h}=50 \mathrm{~mm})$.

\subsection{Heat Loss in Influencing Zone}

Using two-dimensional steady result, the total heat flow $Q$ is:

$Q=\int q d x$

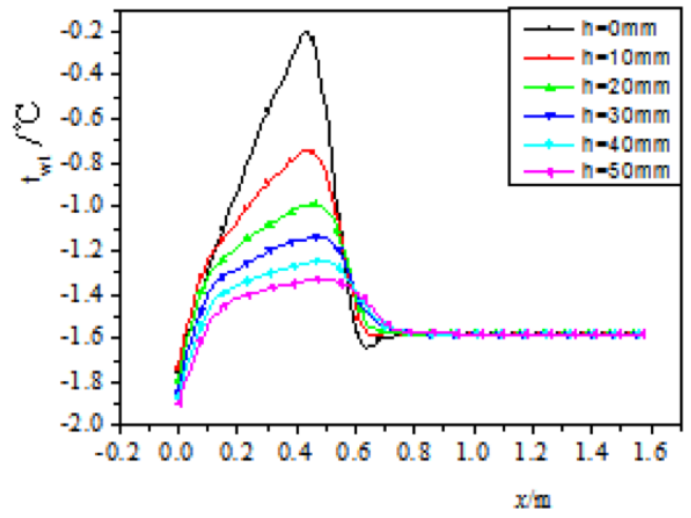

Fig. (3). Temperature of different models.

Additional heat flow $\Delta Q_{B}$ in thermal bridge is:

$\Delta Q_{B}=Q-q_{0} \cdot l$

Additional heat flow $\Delta Q_{B e x}$ in influencing zone is:

$\Delta Q_{B \in}=\int_{D}\left(q-q_{0}\right) d x$

The degree of heat loss in influencing zone of thermal bridge can be represented:

$\beta=\frac{\Delta Q_{B e x}}{\Delta Q_{B}} \times 100 \%$

In the equation, $q_{0}$ represents the density of heat flow in general place, $l$ represents the length of outer surface. D represents the influencing zone of thermal bridge. The heat flow of corner column is shown in Fig. (4) (take $\mathrm{h}=50 \mathrm{~mm}$ for example). The heat flow of different models is shown in Fig. (5).
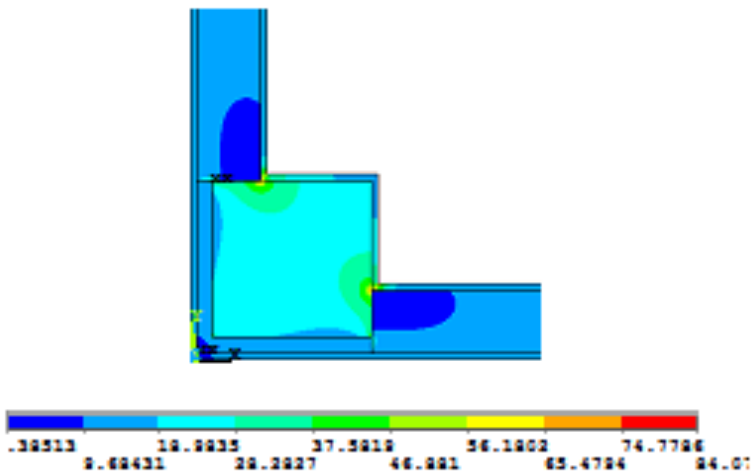

Fig. (4). Heat flow of corner $(\mathrm{h}=50 \mathrm{~mm})$.

Through the calculation, additional heat flow in influencing zone of thermal bridge, and the degree of heat loss in influencing zone of thermal bridge is shown in Table 1.

As is shown in Table 1, for corner column of selfinsulation system, when the thickness of insulation layer is $0 \mathrm{~mm}$, the degree of heat loss in influencing zone of thermal bridge is $5.6 \%$, when the thickness is $50 \mathrm{~mm}$, it is $20.4 \%$. That is, with the thickness of insulation layer increasing, the degree of heat loss in influencing zone of thermal bridge is increasing, heat flow in influencing zone of thermal bridge is obvious. 
Table 1. Degree of heat loss in influencing zone of thermal bridge.

\begin{tabular}{|c|c|c|c|c|c|c|}
\hline Minimum inner surface temperature $\left({ }^{\circ} \mathrm{C}\right)$ & 11.19 & 12.34 & 13.10 & 13.66 & 14.11 & 14.47 \\
\hline Heat flow in influencing zone $\mathrm{q}_{0}\left(\mathrm{~W} / \mathrm{m}^{2}\right)$ & 9.74 & 9.74 & 9.74 & 9.74 & 9.74 & 9.74 \\
\hline Total heat flow Q (W) & 50.07 & 44.78 & 41.37 & 38.85 & 36.95 & 35.34 \\
\hline Additional heat flow in influencing zone $\Delta \mathrm{Q}_{\mathrm{Bex}}(\mathrm{W})$ & 1.53 & 1.31 & 1.28 & 1.22 & 1.05 & 0.97 \\
\hline$\alpha=\Delta Q_{B} / Q(\%)$ & 54.3 & 33.4 & 27.5 & 22.3 & 17.8 & 13.5 \\
\hline$\beta=\Delta Q_{B e x} / \Delta Q_{B}(\%)$ & 5.6 & 8.8 & 11.3 & 14.1 & 16.0 & 20.4 \\
\hline $\begin{array}{l}\text { Average heat conductivity coefficient } \overline{K_{m}} \\
\qquad\left[\mathrm{~W} /\left(\mathrm{m}^{2} \cdot \mathrm{K}\right)\right]\end{array}$ & 0.824 & 0.732 & 0.668 & 0.627 & 0.592 & 0.563 \\
\hline
\end{tabular}

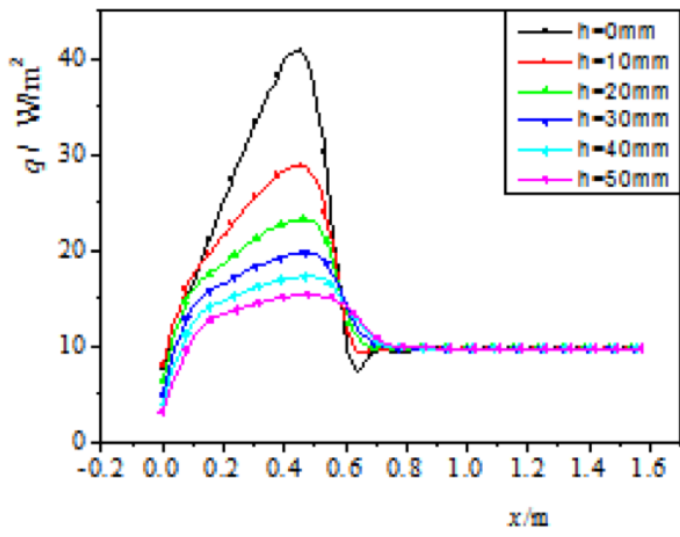

Fig. (5). Heat flow of different models.

\section{CONCLUSION}

The self-insulation system is taken as the research object, and the two-dimensional steady heat transfer of corner column is analyzed using ANSYS. The following conclusions are obtained:

When the thermal bridge is without thermal insulation treatment, influencing zone of thermal bridge is $80 \mathrm{~mm}$, and when the thickness of insulation layer is more than $20 \mathrm{~mm}$, it is about $160 \mathrm{~mm}$.

Additional heat flow in influencing zone accounts for more than $20 \%$ of additional heat flow in thermal bridge, heat flow in influencing zone of thermal bridge is obvious, so the problem of heat loss in influencing zone of thermal bridge should be brought to the forefront.

\section{CONFLICT OF INTEREST}

The authors confirm that this article content has no conflict of interest.

\section{ACKNOWLEDGEMENTS}

The work is supported by the National Science and Technology Supporting Project (No. 2011BAJ03B03), and the Wuhan Science and Technology Bureau Project (No.2014070504020242).

\section{REFERENCES}

[1] S. Li, and H. Wang, "Building energy consumption status and energy saving measure review in China," Environment Science and Management, vol. 33, no. 02, pp. 6-9, 2008.

[2] C. Xu, Influence of External Structure in Residential Buildings on Indoor Thermal Environment and Building Energy Consumption, Chongqing University: Chongqing, 2008.

[3] H. Wang, Analysis of Thermal Characteristics and Energy Consumption of Composite Wall, Harbin Institute of Technology: Harbin, 2007.

[4] A. Adnan, "Local/global analysis of transient heat transfer from building foundations," Building and Environment, vol. 39, no. 5, pp. 495-504, 2004.

[5] A.BenLarbi, "Statistical modeling of heat transfer for therma bridges of building," Energy and Buildings, vol. 37, no. 9, pp. 945 951, 2005.

[6] D. Jia, Heat Transfer Analysis and Optimization of Typical Thermal Bridge in Self-insulation System in Hot Summer and Cold Winter Area, Zhejiang University: Zhejiang, 2013.

[7] Y. Nan, Y. Feng, and J. Gu, "Numerical simulation and experimental study on thermal bridge of building structure," Construction Technology of Low Temperature, vol. 3, pp. 110-111, 2007.

[8] W. Mao, L. Hong, and J. Xu, "Influencing zone and its optimization of the thermal bridge of typical column in single-insulation wall," Chongqing Structure, vol. 12, no.10, pp. 50-52, 2011.

[9] K. Li, and Z. Xu, "Numerical analysis of three dimensional unsteady heat transfer of thermal bridge," Structure Science, vol. 23, no. 12, pp. 35-38, 2007.

[10] H. Tian, and W. Cao, "Numerical simulation of three dimensional heat transfer of thermal bridge," Building Energy And Environment, vol. 30, no. 2, pp. 9-11, 2011 .

Received: February 03, 2015

Revised: April 03, 2015

Accepted: May 25, 2015

(C) Dai et al.; Licensee Bentham Open.

This is an open access article licensed under the terms of the (https://creativecommons.org/licenses/by/4.0/legalcode), which permits unrestricted, noncommercial use, distribution and reproduction in any medium, provided the work is properly cited. 